\title{
Use of active video games with or without videoconferencing on health outcomes in adolescent and young adult cancer survivors: a systematic review
}

\author{
Ursela Christopherson ${ }^{1}$ - Stephanie J. Wells ${ }^{2}$ - Nathan Parker ${ }^{3}$ - Elizabeth J. Lyons ${ }^{4} \cdot$ Michael D. Swartz ${ }^{5}$. \\ Anna Blozinski ${ }^{5} \cdot$ Karen Basen-Engquist $^{3}$ - Susan Peterson ${ }^{3} \cdot$ Maria C. Swartz $^{2}$ (D)
}

Received: 26 December 2020 / Accepted: 26 May 2021 / Published online: 4 June 2021

(C) The Author(s), under exclusive licence to Springer Science+Business Media, LLC, part of Springer Nature 2021

\begin{abstract}
Purpose Adolescent and young adult (AYA) cancer survivors experience greater functional deficits compared to non-cancer peers or older survivors with a similar diagnosis. Physical activity (PA) is a key strategy for mitigating functional decline, and motivation and peer support are critical PA facilitators in AYA cancer survivors. Active video games (AVGs) may be a "gateway" method to promote PA. Further, integrating AVGs into group videoconferencing, a medium used by AYAs to socialize, can capitalize on peer support needed for PA motivation. Thus, we examined the use of AVGs and/or videoconferencing in PA interventions that included AYA survivors and the effect on physical function and health outcomes.

Methods Seven electronic databases were searched from incept to January 2020. Search terms included videoconferencing, video games, exercise, and cancer. The protocol is registered on PROSPERO: CRD42020163491. Two reviewers evaluated eligibility and methodological quality using Cochrane's risk of bias tools.

Results Six unique studies were included with 97\% reviewer agreement. All used AVGs, none used videoconferencing alone, and one used both. Study designs and outcome measures were heterogeneous. Only one study solely targeted AYA survivors. Most were low to medium quality. Few showed significant improvements in quality of life (QOL) and fatigue $(\mathrm{n}=3)$, coordination/balance $(n=2)$, and aerobic capacity $(n=1)$.

Conclusions PA interventions using AVGs and/or videoconferencing may improve QOL and fatigue, but evidence on function is lacking. Rigorous interventions targeting AYA survivors are needed.

Implications for Cancer Survivors Using AVGs and/or videoconferencing to facilitate PA may improve QOL and fatigue.
\end{abstract}

Keywords Active video games $\cdot$ Adolescent and young adult $\cdot$ Physical function $\cdot$ Cancer $\cdot$ Systematic review

\author{
Maria C. Swartz \\ mchang1@mdanderson.org \\ Ursela Christopherson \\ uschrist@utmb.edu \\ Stephanie J. Wells \\ sjwells1@mdanderson.org \\ Nathan Parker \\ nhparker@mdanderson.org \\ Elizabeth J. Lyons \\ ellyons@utmb.edu \\ Michael D. Swartz \\ Michael.d.swartz@uth.tmc.edu \\ Anna Blozinski \\ Anna.L.Blozinski@uth.tmc.edu
}

Karen Basen-Engquist

kbasenen@mdanderson.org

Susan Peterson

speterso@mdanderson.org

1 Division of Rehabilitation Sciences, The University of Texas Medical Branch, Galveston, TX, USA

2 Department of Pediatrics Research, The University of Texas MD Anderson Cancer Center, Houston, TX, USA

3 Department of Behavioral Science, The University of Texas MD Anderson Cancer Center, Houston, TX, USA

4 Department of Nutrition and Metabolism, The University of Texas Medical Branch, Galveston, TX, USA

5 Department of Biostatistics and Data Science, The University of Texas Health Science Center at Houston, Houston, TX, USA 


\section{Introduction}

Adolescent and young adult (AYA) cancer survivors are a medically underserved population [1] recognized by the National Cancer Institute [2] and the American Cancer Society [3]. The age range for this population has been defined as 15 to 39 years of age $[2,4]$. With advances in diagnosis and treatment during the past four decades, the 5-year survival rate has improved significantly among AYA cancer survivors [5, 6]. However, increased survival comes with a cost. Cancer and cancer-related treatment are associated with a myriad of deleterious short- and long-term side effects that can negatively impact physical function and accelerate functional decline [7]. Notably, a recent study on AYA cancer survivors indicated a high rate of physical concerns $(88 \%)$ and emotional concerns $(79 \%)$, yet fewer than $50 \%$ reported that their concerns have been addressed by their healthcare team [8].

Functional impairment is defined as the inability to carry out certain functions as a result of an illness or injury [9]. When unaddressed, it can contribute to a cascade of further functional decline and may potentially compound the lifealtering problems faced by AYA cancer survivors, increasing healthcare utilization and risk for both loss of independence and early mortality [10].

Functional impairment also decreases survivors' ability to fulfill life roles due to post-treatment effects which may lead to changes in ambulation, posture, and coordination [11]. These impairments are associated with increased risk of morbidity and mortality, and decreased quality of life (QOL), independent of functional decline (e.g., progressive weakness secondary to non-use) [11-13].

In fact, data that included adolescent-aged childhood cancer survivors indicated that cumulative frequency of severe, disabling, or life-threatening health conditions by age 50 is approximately twice that of their cancer-free peers [14]. AYA survivors are also at 10.4-fold increased risk for mortality in comparison to their matched non-cancer cohort and this elevated risk persists 20 years or longer [15].

Along with treatment exposures (i.e., radiation), current and former physical activity (PA) engagement is significantly correlated with frailty [14]. Thus, PA is a key strategy to mitigate functional decline and improve physical function [16], yet fewer than $50 \%$ of AYA cancer survivors meet PA recommendations [17]. Some challenges faced by AYA cancer survivors, such as balancing demands of schooling, caring for aging parents and young children, meeting work demands, and managing their own health-related issues [18], may be similar to those experienced by cancer survivors older than 39 years old. However, these stressors are likely amplified in AYA cancer survivors because they face these challenges with fewer resources (e.g., difficulty finding peer support) and experience significantly greater symptom burden than older survivors with a similar cancer diagnosis $[19,20]$.
Additionally, AYA survivors may be geographically isolated from family and other support systems as a result of moving away to begin school or work, and thus must learn to face these issues on their own for the first time. Altogether, these challenges can exacerbate functional decline and can impact how they respond to PA interventions. Therefore, tailored interventions that are responsive to the needs of AYA cancer survivors are needed.

The use of active video games (AVGs) may be a potential "gateway" method to reach and promote PA among AYA cancer survivors [21]. AVGs have been shown to increase motivation to participate in PA in adult and pediatric populations, both in amount and intensity, by acting as a bridge from playing conventional video games to engaging in PA [21,22]. Additionally, AVGs can lead to better health behaviors by improving self-esteem and self-efficacy for engaging in PA, allowing for the development of skills necessary for participation in PA, and providing social support when played with others [21]. AYA cancer survivors have expressed that safety and physical limitations, resulting from treatment, are barriers to PA [23]. These can be addressed by using AVGs to encourage trials of various activities.

Considering that online group video game play and socialization are popular among AYAs, integrating AVGs into group videoconferencing can potentially capitalize on peer support needed to increase motivation for PA and accommodate AYA cancer survivors' desire to participate in interventions remotely [24]. The integration of video game play and group videoconferencing is not new among gamers. The combination has been in use since 2017 through Twitch, a popular live streaming service typically used for live broadcasts of video game play alongside video of the player(s). This feature was added to enhance game play experience among gamers [25, 26]. However, group videoconferencing has now become more accessible with rapid advances in technology. The worldwide COVID-19 pandemic further made videoconferencing (e.g., Zoom, FaceTime, Google Meet, WhatsApp) commonplace for individuals to interact for socialization, exercise, work, and telemedicine purposes [27]. Therefore, combining group videoconferencing with AVG activities would provide peer support, a critical PA facilitator among AYA cancer survivors as they navigate transition challenges [28-32], and may help to reduce access-related limitations [33] to motivate and promote PA engagement. Thus, this systematic review aims to examine how AVGs and/or videoconferencing were used in PA interventions that included AYA cancer survivors and the effect on physical function and health outcomes.

\section{Methods}

This review was conducted in accordance with the 2009 Preferred Reporting Items for Systematic Reviews and 
Meta-Analyses (PRISMA) [34]. The details of the protocol for this systematic review, as well as an example of the Medline OVID search strategy, were registered on PROSPERO CRD42020163491 (International Prospective Register of Systematic Reviews; http://www.crd.york.ac.uk/ PROSPERO/).

\section{Data sources and searches}

A comprehensive search of the published literature was constructed collaboratively by MCS and a medical research librarian who is trained in systematic reviews. Published articles were collected from seven databases (Medline (Ovid platform), Embase (Ovid platform), PubMed, Scopus, CINAHL, PsycINFO, and Web of Science). The search was conducted from database inception to January 2020. Search terms included videoconferencing," "video games," "virtual reality," "exercise," "cancer," and related words. Searches were not restricted by language, study design, or any other limit, to ensure that we were able to capture all possible articles. The complete search strategy for Medline Ovid is available on PROSPERO. If applicable, additional articles were retrieved through searching the references of included papers and other review articles that evaluated technology-based interventions to improve physical function among AYA survivors of cancer.

\section{Inclusion criteria}

\section{Participants}

Our systematic review evaluated studies that used AVG and/ or videoconferencing as a PA intervention in individuals with cancer. Study participants could have any cancer diagnosis and be at any stage of treatment or survivorship. Participants may have included patients with caregivers, and/or family. Studies with age ranges below and above AYA but included participants aged 15-39 years were included. Our reasoning for this stemmed from the fact that AYA cancer survivors are often grouped together with either pediatric or adult cancer survivors in cancer treatment [3], and we suspected this might also be the case in studies on cancer survivors.

\section{Interventions}

Our review included interventions that use AVGs in the console or application (app) formats and/or AVG interventions that integrated videoconferencing to deliver the PA intervention. For exercise interventions, the following information was abstracted: exercise modality, study length, frequency, duration of the session, and report of any adverse events.

\section{Exclusion criteria}

Articles were excluded if they were a type of review article (e.g., systematic review, scoping review), did not involve human subjects (e.g., animal studies), or were news briefs, bulletins, conference sessions, or abstracts. Studies that did not enroll any participants aged 15 to 39 years within their cohort were excluded. Studies that used videoconferencing for telerehabilitation but did not report physical function or physical activity assessments were excluded. We contacted the primary author by e-mail if published information was unclear regarding the age range of enrolled participants $[35,36]$.

\section{Comparators}

We considered studies that included comparisons to healthy controls (i.e., case-control, cohort studies), participants serving as their own control (i.e., cross-over), standard of care (i.e., randomized control), or groups that did not receive an intervention (i.e., wait-listed, education handout).

\section{Outcomes}

We considered studies that used AVGs and/or integrated videoconferencing, with the primary outcomes of interest being physical function and cancer-related fatigue. Physical function assessments included objective and subjective measures that evaluated PA, mobility, and performance capacity. CRF assessments included subjective reporting of CRF at baseline and at follow-up. Secondary outcomes of interest included QOL and behavior change methodology. QOL assessments included changes in subjective QOL measures between baseline and follow-up.

\section{Types of studies}

We included articles with experimental and quasiexperimental study designs (e.g., randomized controlled trials [RCT]), non-randomized controlled trials, pilot studies, feasibility, and case studies that used AVGs, and studies that combined AVGs and videoconferencing to promote PA and improve physical function.

\section{Study selection}

Duplicates were removed based on the title, abstract, and full text. The research team then reviewed the remaining articles for eligibility during screening. Articles were screened in two phases in a blinded, independent manner by two reviewers (UC and SW). Rayyan [37], a web- and mobile app-based systematic review tool, was used to determine if all inclusion and exclusion criteria were met. Any disagreement in study selection was settled by discussion between the two reviewers 
and authors MCS and NP. A data abstraction form was completed for each full-text study in order to synthesize heterogeneity of the interventions, study designs, and results. Furthermore, we used an abstraction form to extract information on cancer diagnosis, type and stage of cancer, time since diagnosis, sample size, age, race/ethnicity distribution, other participant characteristics, type of intervention, study characteristics, and results.

\section{Risk of bias assessment}

We used Cochrane's Risk of Bias tool (RoB 2) for randomized controlled trials [38]. The RoB 2 assesses bias across five domains: randomization process, deviation from the intended intervention, missing outcome data, outcome measurement, and selective reporting. An overall bias is assessed and classified as "low risk," "some concerns," or "high risk" of bias.

For non-randomized studies, we used Cochrane's Risk of Bias In Non-randomized Studies - of Interventions (ROBINSI) tool [39]. The ROBINS-I assesses bias across seven domains: confounding, selection of participants into the study, classification of interventions, deviations from intended interventions, missing outcome data, measurement of outcomes, and selection of reported results. The overall risk of bias is assessed based on the previous domains and classified as "low risk," "moderate risk," "serious risk," or "critical risk" of bias.

\section{Results}

\section{Study characteristics}

The study selection process and study characteristics are outlined in Fig. 1. A total of 790 articles were identified, and 301 duplicates were removed by the medical research librarian. Thus, a total of 489 unique records were identified and imported into the Rayyan system: 135 (Medline), 128 (Embase), 18 (PubMed), 54 (CINAHL), 15 (PsycINFO), 97 (Scopus), and 42 (Web of Science). Of those 489 records, 62 were found to be duplicates, leaving 427 individual articles to be screened by the team. Most articles were removed after screening titles and abstracts $(n=397)$. Results from this screening yielded eight full-text articles from six individual studies. The level of agreement between reviewers (UC and SW) was $97 \%$. The six studies were conducted in five countries (Brazil [35, 40], Finland [41], USA [42, 43], Germany [44], and Sweden $[45,46])$ and were published from 2013 to 2019.

Studies had a median sample size of $n=27$. The sample sizes ranged from eight [43] to $45[35,40]$. Two of the six studies included over $50 \%$ female participants $[35,40,45$, 46], and only one study reported race, weight, education, and income [43]. Two studies provided data on body mass index (BMI) $[35,40,43]$. Two studies included adolescents (age 15-17 years) $[41,45,46]$, and four included adolescents and young adults (age $18-39$ years) [35, 40, 42-44]. Only one study specifically targeted the AYA cancer population [42]. The forms of cancer varied across all studies, and each study included multiple cancer types. Time since cancer diagnosis was reported in five articles $[35,40,41,45,46]$ ranging from 1.4 months to 5 years.

Of the six studies, one was an RCT [41], two were a quasiexperimental control study $[35,40]$, two were RCT pilot studies [44-46], one was an uncontrolled pilot study [42], and one was a single-arm feasibility study [43]. Trial length varied. One trial was 6 weeks [43], one was 10 weeks [45, 46], two were $8-10$ weeks $[35,40,41]$, and two were performed during a procedural hospital stay of mean 23.5 days following hematopoietic stem cell transplantation (HSCT) [42, 44]. Four studies had control groups, which included healthy controls without cancer history who also received the AVG intervention $[35,40]$, cancer patients who received general PA recommendations of 30 min per day [41], a wait-list control group [45, 46], and standard-of-care physical therapy sessions [44]. Two studies had no control group [42,43].

\section{The use of AVGs and/or videoconferencing in PA interventions}

Two commercially available AVG devices were used: the Xbox 360 Kinect ${ }^{\circledR}[35,40]$ and the Nintendo Wii ${ }^{\circledR}$ [41-46]. The Xbox 360 Kinect $®$ system used a camera to sense player movement, whereas the Nintendo Wii ${ }^{\circledR}$ system used motion-sensing game controllers. For some games such as Wii Fit under Nintendo Wiiß, a weight-sensing balance board is also used to detect player movement. All AVG sessions were performed individually. Videoconferencing was not widely used to deliver PA interventions. Among the selected articles, only one study used videoconferencing for weekly individual coaching sessions with a research nurse in an effort (1) to increase compliance with the AVG prescription, (2) to encourage exploration of game use, and (3) to interact with the participant to play new games together [45, 46]. We found that videoconferencing was not used to deliver individual or group AVG sessions.

\section{The use of behavior change techniques}

The use of behavior change techniques to promote increased AVG use was not incorporated consistently among the selected articles. Two studies used some form of behavioral coaching such as a single motivational phone call at the midpoint of the 8-week intervention [41], and weekly motivational coaching with a research nurse $[45,46]$. Only one study specified the type of behavior change methods integrated into the intervention design. Wang and colleagues (2019) incorporated strategies in both the development and the 


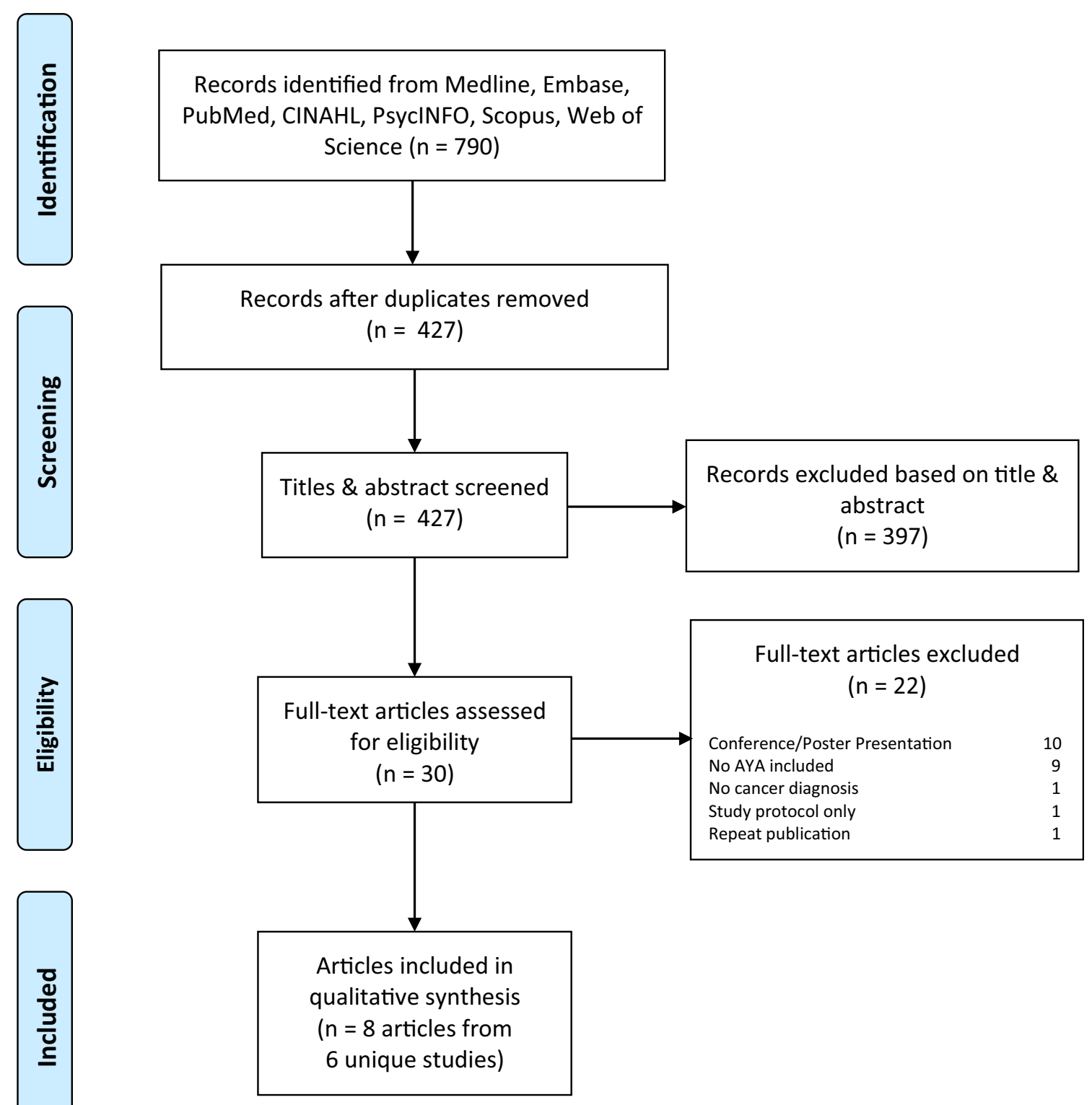

Fig. 1 Study selection process. Flow diagram of identified publications with number of articles removed displayed in the far right column

implementation of the intervention to promote task selfefficacy and PA enjoyment. The development of the intervention included activating mastery experiences (by providing challenging tasks and giving feedback), guided practice (prompting participants to perform the activities), goal setting, and setting graded tasks (prescribing PA at lower levels and increasing over time to meet PA recommendations). Implementation of the intervention included guided practice, behavior self-monitoring, verbal persuasion through Wii Fit ${ }^{\circledR}$ messages and from the nurse interventionist, and planning coping responses to barriers. The authors incorporated strategies to enhance PA enjoyment included goal setting (including enjoyable games in the exercise prescription) and promoting intrinsic motivation [43].

\section{Physical function and physical activity (PA) measures}

All studies assessed fitness or physical function and PA. Physical function measures varied for each study and included surface electromyography using maximal voluntary isometric contractions (MVICs) [35], ankle strength via dynamometry [35], motor performance via the Movement-ABC2 [41], Timed Up and Go (TUG) [42], Six Minute Walk Test (6MWT) [42, 43], Bruininks-Oseretsky Test of Motor Performance (BOT-2) [45], the Assessment of Motor Process Skills (AMPS) [46], the Two Minute Walk Test (2MWT) [44], handgrip strength via handgrip dynamometry [43, 44], shoulder range of motion (ROM), Lawton Instrumental Activities of Daily Living (IADL) Scale, and 
Berg Balance Scale assessment [43]. PA measures included AVG weekly session attendance and minutes per week of participation [35], step counts per hour (as measured by Fitbit Ultra accelerometers worn around the waist) [41], selfreported type and duration of PA using an activity log [42], Sensewear Pro 2 Armband assessing metabolic equivalents (METs) [45, 46], and energy expenditure assessed via the Human Activity Profile [44].

\section{Fatigue and other health outcome measures}

Three studies evaluated CRF. Similar to the PA and physical function measures, CRF was assessed using a variety of selfreported scales. The PedsQL ${ }^{\text {TM }}$ Multidimensional Fatigue Scale questionnaire proxy report was used in one study [41], while the Brief Fatigue Inventory (BFI) was used in another [43]. In the third study, fatigue was assessed using the Functional Assessment of Chronic Illness Therapy-Fatigue (FACIT-F) and the Functional Assessment of Cancer Therapy - Fatigue (FACT-F) [35, 40].

Two studies out of six assessed QOL. While one study [42] used the Behavioral, Affective, and Somatic Experiences Scale-Child version (BASES-C), another study [44] used both the Functional Assessment of Cancer Therapy-Bone Marrow Transplantation (FACT-BMT) and 36-Item Short Form Survey (SF-36) to capture QOL.

\section{Changes in physical function and health outcomes}

Changes in function and fitness demonstrated improvements in MVIC, 6MWT, IADLs, balance, grip strength sum, shoulder forward flexion, and body coordination [35, 43, 45, 46]. Contrastingly, two studies found no significant changes in function as measured by physical activity minutes per day $[41,42]$, and one study reported that grip strength decreased in both intervention and control patients [44].

Three studies found no significant differences in PA type and duration, moderate and vigorous physical activity (MVPA) levels, or METs post-intervention [41, 42, 44]. Two studies collected PA data as a means of determining intervention adherence, not to analyze changes in lifestyle PA [35, 43]. Two studies found significant improvements in self-reported fatigue, as measured by fatigue subscales of the FACT-F, and CRF severity levels $[35,40,43]$ with one study [40] that showed improvements in fatigue after 10 AVG sessions, but no further improvement after another 10 sessions. However, Hamari et al. found no significant differences in fatigue PedQL scores between intervention and control groups, pre and post-intervention [41].

Significant improvements were seen in QOL scores on the FACT-G, SF-36, and FACT-BMT in the AVG groups [40, 44]. Subcategories within the FACT-BMT that showed improvement included Physical Well-Being (PWB), Emotional Well-
Being (EWB), and Functional Well-Being (FWB) [44]. PWB scores decreased significantly from baseline (day of hospital admission) to second follow-up (14 days post-HSCT) and then increased from the second follow-up to the final assessment (100 days post-HSCT) in both HSCT groups. At the same time, EWB and PWB increased significantly only in the AVG group [44]. Rosipal and colleagues saw an increase in BASES-C scores (higher scores equate to lower QOL) in the AVG group during hospitalization for HSCT. However, scores steadily decreased towards baseline as participants were close to discharge and changes were not significant [42]. Study results and characteristics are summarized in Table 1.

\section{Risk of bias assessment}

Based on the results from the RoB 2 for the four randomized studies (Table 2), two were rated as "High" risk $[41,44]$ and the other two were rated as having "Some concerns" of risk [45, 46]. The major concerns that warranted the "High" risk judgment were in the domains of deviations from the intended intervention due to non-compliance, missing outcome data, and selection of the reported results. Only two performed an intention to treat analysis and incorporated blinding of the outcome assessors $[45,46]$. Using the ROBINS-I for the non-randomized studies, three out of four were rated as "Serious" risk [35, 40, 42], and the other as "Moderate" risk [43] (Table 3). The primary concerns that warranted the "Serious" risk judgment were in the domains of missing data (only completer analysis performed) and the absence of blinding for the outcome assessors.

$2 M W T$, Two Minute Walk Test; $6 M W T$, Six Minute Walk Test; $A D L$, activity of daily living; $A M P S$, assessment of motor and process skills; $A V G$, active video games; $B C$, behavior change; $B F I$, Brief Fatigue Inventory; BOT-2, BruininksOseretsky Test of Motor Proficiency Ed. 2; Con, control group; $C R F$, cancer-related fatigue; Exp, experimental (intervention) group; FACT-BMT, Functional Assessment of Cancer Therapy-Bone Marrow Transplantation; FACT-F, Functional Assessment of Cancer Therapy: Fatigue; FACT$G$, Functional Assessment of Cancer Therapy: General; $F W B$, Functional Well-Being; $H S C T$, hematopoietic stem cell transplant; $I A D L$, Instrumental Activities of Daily Living; $M E T$, metabolic equivalent of task; MVIC, maximal voluntary isometric contraction; $M V P A$, moderate to vigorous physical activity; $N A$, not applicable; $N R$, not reported; $P A$, physical activity; $P F$, physical function; $P W B$, Physical Well-Being; $Q O L$, quality of life; $R O M$, range of motion; $s E M G$, surface electromyography; $S F-36$, 36-Item Short Form Survey

\section{Discussion}

Overall, our systematic review found that only one study integrated videoconferencing into a PA intervention that 
Table 1 Study characteristics

\begin{tabular}{|c|c|c|c|c|c|c|}
\hline $\begin{array}{l}\text { Author } \\
\text { (year) }\end{array}$ & Study design & Intervention & Study population & Primary measures & $\begin{array}{l}\text { Secondary } \\
\text { measures }\end{array}$ & Summary of results \\
\hline $\begin{array}{l}\text { Alves et al. } \\
\qquad(2017 ; \\
\text { 2018) } \\
\text { Brazil }\end{array}$ & $\begin{array}{l}\text { Quasi-experimental } \\
\text { control }\end{array}$ & $\begin{array}{l}\text { AVG type: } \text { Xbox } \\
\begin{array}{l}\text { Kinect } \\
\text { reps per session })\end{array} \\
\text { Videoconferencing: } \\
\begin{array}{l}\text { None used } \\
\frac{\text { Setting: University }}{\text { lab }}\end{array} \\
\frac{\text { Session: } 8 \text { weeks; }}{2-3 \times / w k, 20} \\
\text { sessions total }\end{array}$ & $\begin{array}{l}\frac{\text { Age range: } 24-76 \text { yrs }}{\text { (mean: } 57.13 \pm 16.7 ;} \\
63.29 \pm 7.3 ; 56.73 \pm 11.9 \\
\text { yrs) } \\
\frac{\text { Sample size: } \mathrm{n}=45(\mathrm{n}=15,}{15)} \\
\frac{\text { Number of groups: } 3}{\text { Control group: (healthy) }} \\
\mathrm{n}=15 \\
\frac{\text { Cancer diagnosis: } \mathrm{GI},}{\text { breast, abd/pelvic, }} \\
\text { oropharyngeal, other }\end{array}$ & $\begin{array}{l}\text { PF: sEMG; ankle } \\
\text { dynamometry } \\
\text { CRF: FACIT-F } \\
\text { (higher scores = } \\
\text { less fatigue); } \\
\text { FACT-F }\end{array}$ & $\begin{array}{l}\text { QOL: } \\
\text { FACT-G } \\
\text { BC: None }\end{array}$ & $\begin{array}{l}\text { Significant decrease in } \\
\text { fatigue subscale in } 2 \\
\text { experimental groups } \\
\text { compared to controls: } \\
\text { Baseline: (Exp1: } 35.7 \pm \\
\text { 12; Exp2: } 34.1 \pm 12 ; \\
\text { Con:45.3 } \pm 6) \\
8 \text { wks: (Exp1: } 47 \pm 4 ; \\
\text { Exp2: } 45.4 \pm 7 \text {; Con: } \\
\text { 47.5 } \pm 5)(p=0.001) \\
\text { Significant increase in } \\
\text { MVIC (ankle strength) } \\
\text { in Exp groups vs Con } \\
\text { Significant improvement } \\
\text { in FACT-G (QOL) } \\
\text { mean scores in both } \\
\text { Exp groups: } \\
\text { Baseline: (Exp1: } 35.7 ; \\
\text { Exp2: } 34.1 ; \text { Con: } 45.3 \text { ) } \\
\text { After 20 sessions: (Exp1: } \\
\text { 46.8; Exp2: } 44.6 ; \text { Con: } \\
\text { 47.3) (p<0.001) }\end{array}$ \\
\hline $\begin{array}{l}\text { Hamari et al. } \\
\qquad(2018) \\
\text { Finland }\end{array}$ & $\mathrm{RCT}$ & $\begin{array}{l}\frac{\text { AVG type: Nintendo }}{\text { WiFiFitM }^{\mathrm{TM}} \text { games }} \\
\frac{\text { Videoconferencing: }^{\text {None used }}}{\text { Nong: Hospital \& }} \\
\frac{\text { Setting: }}{\text { home-based }} \\
\frac{\text { Session: } 8 \text { weeks; } 30}{\text { min/day; }} \\
\text { Motivational } \\
\text { phone call at } 4 \\
\text { weeks; } \\
\text { Maintain PA diary }\end{array}$ & $\begin{array}{l}\frac{\text { Age range: }}{3-16} \text { yrs } \\
\text { (Mean: } 7.8 \text { yrs) } \\
\text { Sample size: } n=36 \\
\text { Number of groups: } 2 \\
\text { Control group: } \mathrm{n}=19 \\
\text { Cancer diagnosis: Acute } \\
\text { lymphocytic leukemia, } \\
\text { Wilms tumor, Burkitt } \\
\text { lymphoma, } \\
\text { non-Hodgkin and } \\
\text { Hodgkin lymphoma, } \\
\text { other }\end{array}$ & $\begin{array}{l}\text { PF:M-ABC2; } \\
\text { accelerometer; } \\
\text { MET } \\
\text { Questionnaire } \\
\text { (MET } \\
\text { hrs/week) } \\
\text { CRF: Peds-QL } \\
\text { proxy reports }\end{array}$ & $\begin{array}{l}\text { QOL: None } \\
\text { BC: None }\end{array}$ & $\begin{array}{l}\text { Median accelerometer } \\
\text { count and physical } \\
\text { activity min/day did } \\
\text { not differ significantly } \\
\text { ( } p=0.63, p=0.95, \\
\text { respectively) } \\
\text { No significant group } \\
\text { differences in } \\
\text { M-ABC } 2 \text { and } \\
\text { Peds-QL fatigue } \\
\text { scores ( } p=0.77, \\
p=1.00, \text { respectively) }\end{array}$ \\
\hline $\begin{array}{l}\text { Rosipal et al. } \\
\quad(2013) \\
\text { TX, USA }\end{array}$ & Pilot study & $\begin{array}{l}\text { AVG type offered: } \\
\text { Nintendo } \\
\text { WiiFit }{ }^{\mathrm{TM}} \text {, Dance } \\
\text { Dance Revolution } \\
\text { Videoconferencing: } \\
\text { None used } \\
\text { Setting: In hospital } \\
\text { Session: Length of } \\
\text { stay (17-34 days); } \\
\text { encouraged to } \\
\text { perform in room } \\
\text { PA } 3 \times / \text { wk, total of } \\
\geq 60 \text { min; } \\
\text { Using either: AVG, } \\
\text { weight training, or } \\
\text { basketball } \\
\text { Maintain PA diary } \\
\text { Continue with } \\
\text { hospital lead } \\
\text { PT/OT }\end{array}$ & $\begin{array}{l}\text { Age range: } 19-25 \mathrm{yrs} \\
\text { (mean: } 22.1 \pm 2.4 \mathrm{yrs}) \\
\text { Sample size: } \mathrm{n}=18 \\
\text { Number of groups: } 1 \\
\text { Control group: None } \\
\text { Cancer diagnosis: } \\
\text { Leukemia, sickle cell, } \\
\text { Hodgkin lymphoma, } \\
\text { germ cell, mycosis } \\
\text { fungoides }\end{array}$ & $\begin{array}{l}\text { PF: TUG, } 6 \text { MWT, } \\
\text { PA log (activity } \\
\text { type \& } \\
\text { duration) } \\
\text { CRF: None }\end{array}$ & $\begin{array}{l}\text { QOL: } \\
\text { BASES-C } \\
\text { BC: None }\end{array}$ & $\begin{array}{l}\text { 6MWT (feet): } \\
\text { Admission: } 1548 \pm \\
343 \\
\text { Discharge: } 1527 \pm 309 \\
\text { ( } p=0.985) \\
\text { TUG (s): Admission: } \\
6.92 \pm 1.6 \\
\text { Discharge: } 6.66 \pm 1.5(p= \\
0.375) \\
\text { No significant group } \\
\text { differences in } 6 M W T \\
\& \text { TUG } \\
\text { QOL BASES mean } \\
\text { scores: Time } 1: 34.7 ; \\
\text { Time } 2: 41 ; \text { Time } 3: \\
\text { 42.7; Time } 4: 37.2 \\
\text { 1 patient connected with } \\
\text { family online for } \\
\text { AVGs, increased } \\
\text { activity engagement } \\
\text { time. }\end{array}$ \\
\hline $\begin{array}{l}\text { Sabel et al. } \\
\quad(2016 ; \\
\text { 2017) } \\
\text { Sweden }\end{array}$ & $\begin{array}{l}\text { Pilot cross-over } \\
\text { RCT }\end{array}$ & $\begin{array}{l}\frac{\text { AVG Type: }}{\text { Nintendo }} \\
\text { WiiFit }{ }^{\mathrm{TM}} \text { games } \\
\text { Videoconferencing: } \\
\text { 1-on-1 weekly }\end{array}$ & $\begin{array}{l}\frac{\text { Age range: } 7-17 \text { yrs ( } 12.5}{ \pm 2.9 \text { yrs })} \\
\text { Sample size: } n=13 \\
\text { Number of groups: } 2 \\
\text { Control group: wait-list }\end{array}$ & $\begin{array}{l}\text { PF: BOT-2; } \\
\text { AMPS; energy } \\
\text { expenditure } \\
\text { (METs); } \\
\text { MVPA }\end{array}$ & $\begin{array}{l}\text { QOL: None } \\
\text { BC: None }\end{array}$ & $\begin{array}{l}\text { No significant changes in } \\
\text { ADLs, METs, MVPA } \\
\text { Significant increase in } \\
\text { body coordination in } \\
\text { BOT-2 scores Exp }\end{array}$ \\
\hline
\end{tabular}


Table 1 (continued)

\begin{tabular}{|c|c|c|c|c|c|c|}
\hline $\begin{array}{l}\text { Author } \\
\text { (year) }\end{array}$ & Study design & Intervention & Study population & Primary measures & $\begin{array}{l}\text { Secondary } \\
\text { measures }\end{array}$ & Summary of results \\
\hline & & $\begin{array}{l}\begin{array}{l}\text { motivational } \\
\text { coaching with } \\
\text { nurse coordinator }\end{array} \\
\text { Setting: Home-based } \\
\text { Session: } 10-12 \\
\text { weeks; } \geq 5 \\
\begin{array}{l}\text { days } / \text { wk, } \geq 30 \\
\text { min/day }\end{array}\end{array}$ & $\frac{\text { Cancer diagnosis: Various }}{\text { brain tumors }}$ & CRF: None & & \\
\hline $\begin{array}{l}\text { Schumacher } \\
\text { et al. } \\
(2018) \\
\text { Germany }\end{array}$ & $\begin{array}{l}\text { Pilot } \\
\text { RCT }\end{array}$ & $\begin{array}{l}\frac{\text { AVG type: Nintendo }}{\text { WiiFit } \mathrm{TM}_{\mathrm{TM}} \text { games }} \\
\frac{\text { Videoconferencing: }}{\text { None used }} \\
\text { Setting: In hospital } \\
\frac{\text { Session: Length of }}{\text { stay or } 30 \text { days; } 5} \\
\text { days/wk, } 30 \\
\text { min/day }\end{array}$ & $\begin{array}{l}\text { Age range: } 21-68 \text { yrs } \\
\text { (median age: Exp: } 56 \text { yrs; } \\
\text { Con: } 56.5 \text { yrs) } \\
\text { Sample size: } n=31 \\
\text { Number of groups: } 2 \\
\frac{\text { Control group: } \mathrm{n}=17 \text {; usual }}{\text { care w/PT }} \\
\text { Cancer diagnosis: multiple } \\
\text { myeloma, AML/MDS, } \\
\text { other }\end{array}$ & $\begin{array}{l}\text { PF: } 2 \text { MWT, } \\
\text { handgrip } \\
\text { dynamometry; } \\
\text { Human Activity } \\
\text { Profile } \\
\text { CRF: None }\end{array}$ & $\begin{array}{l}\text { QOL: } \\
\text { FACT-B- } \\
\text { MT } \\
\text { SF-36 } \\
\text { BC: None }\end{array}$ & $\begin{array}{l}\text { Significant increase in } \\
\text { vitality score (SF-36) } \\
\text { in Exp (55 to 65) vs } \\
\text { Con ( } 45 \text { to } 50 \text { ); } \\
\text { Significant changes in } \\
\text { FACT-BMT (PWB) } \\
\text { from baseline, and } \\
\text { FWB at follow-up in } \\
\text { Exp } \\
\text { Significant decrease in } \\
\text { handgrip strength in } \\
\text { both groups - control } \\
\text { w/PT: ( } p=0.03 \text { ) and } \\
\text { Exp w/AVG ( } p=0.02) \\
\text { No significant change in } \\
\text { 2MWT or PA }\end{array}$ \\
\hline $\begin{array}{l}\text { Wang et al. } \\
\quad(2019) \\
\text { FL, USA }\end{array}$ & Pilot study & $\begin{array}{l}\frac{\text { AVG type: Nintendo }}{\text { WiiFit }}{ }^{\mathrm{TM}} \text { games } \\
\frac{\text { Videoconferencing: }}{\text { None used }} \\
\text { Setting: Home-based } \\
\frac{\text { Session: } 6 \text { weeks; }}{3-5 \times / \text { wk }} \\
1 \mathrm{hr} \text { weekly home } \\
\text { visit to monitor } \\
\text { safety } \\
\text { 10-min weekly call } \\
\text { after } 6 \text { wks to } \\
\text { monitor adherence }\end{array}$ & $\begin{array}{l}\text { Age range: } 27-73 \mathrm{yrs} \\
\text { (mean: } 57.6 \pm 13.3 \mathrm{yrs}) \\
\text { Sample size: } \mathrm{n}=8 \\
\text { Number of groups: } 1 \\
\text { Control group: None } \\
\text { Cancer diagnosis: Head } \\
\text { and neck, laryngeal }\end{array}$ & $\begin{array}{l}\text { PF: 6MWT; } \\
\text { handgrip } \\
\text { dynamometry; } \\
\text { shoulder ROM, } \\
\text { Berg Balance } \\
\text { Scale; Lawton } \\
\text { IADL } \\
\text { CRF: BFI }\end{array}$ & $\begin{array}{l}\text { QOL: None } \\
\text { BC: Task } \\
\text { self-- } \\
\text { efficacy } \\
\text { and } \\
\text { enhanced } \\
\text { PA } \\
\text { enjoy- } \\
\text { ment }\end{array}$ & $\begin{array}{l}\text { Minimal clinical } \\
\text { important difference } \\
\text { largest in 6MWT: }+40 \\
\text { m (357.2 m to } 408.5 \\
\text { m), and CRF: }-1.1 \\
\text { (5.7 down to 3.7); } \\
\text { Significant improvement } \\
\text { in handgrip strength, } \\
\text { left shoulder forward } \\
\text { flexion, IADLs, and } \\
\text { balance }\end{array}$ \\
\hline
\end{tabular}

2MWT: two minute walk test; 6MWT: six minute walk test; ADL: activity of daily living; AMPS: Assessment of Motor and Process Skills; AVG: active video games; BC: Behavior Change; BFI: Brief Fatigue Inventory; BOT-2: Bruininks-Oseretsky Test of Motor Proficiency Ed. 2; Con: control group; CRF: Cancer Related Fatigue; Exp: experimental (intervention) group; FACT-BMT: Functional Assessment of Cancer Therapy-Bone Marrow Transplantation; FACT-F: Functional Assessment of Cancer Therapy: Fatigue; FACT-G: Functional Assessment of Cancer Therapy: General; FWB: Functional well-being; HSCT: Hematopoietic Stem Cell Transplant; IADL: Instrumental Activities of Daily Living; MET: Metabolic Equivalent of Task; MVIC: Maximal voluntary isometric contraction; MVPA: moderate to vigorous physical activity; NA: not applicable; NR: not reported; PA: physical activity; PF: Physical Function; PWB: Physical well-being; QOL: quality of life; ROM: range of motion; sEMG: surface electromyography; SF36: 36-Item Short Form Survey

included AYA cancer survivors. Videoconferencing was used for a one-on-one coaching session. However, the videoconferencing technology was not used to deliver the individual or group AVG sessions. Additionally, PA interventions that used AVGs and/or integrated videoconferencing with AVG showed promise for improving QOL and fatigue. More rigorous evidence is needed to evaluate the association between PA interventions using AVGs and/or AVGs that integrate with videoconferencing and objective physical function and fitness outcomes. There is also a need for interventions to specifically target the AYA cancer survivors to establish the evidence within this underserved group with unique needs.

To our knowledge, this is the first systematic review to focus specifically on this topic and population. One review by Kopp et al. examined the use of technology to deliver lifestyle behavior interventions addressing chronic disease risk factors in AYA cancer survivors. The primary focus of these studies was PA [33]. Other review articles have 
Table 2 Risk of bias assessment. Results using the RoB 2 Assessment ${ }^{\mathrm{a}}$

\begin{tabular}{llllll}
\hline Sources & \multicolumn{2}{l}{ Risk of bias judgement for domain } & & \multicolumn{1}{c}{$\begin{array}{l}\text { Overall RoB } \\
\text { judgement of } \\
\text { the result }\end{array}$} \\
\cline { 2 - 6 } & $\begin{array}{l}\text { Bias due to } \\
\text { randomization } \\
\text { process }\end{array}$ & $\begin{array}{l}\text { Bias due to } \\
\text { deviations } \\
\text { from the } \\
\text { intended } \\
\text { intervention }\end{array}$ & $\begin{array}{l}\text { Bias due } \\
\text { to missing } \\
\text { outcome } \\
\text { data }\end{array}$ & $\begin{array}{l}\text { Bias in measurement } \\
\text { of the outcome }\end{array}$ & $\begin{array}{l}\text { Bias in } \\
\text { selection of } \\
\text { the reported } \\
\text { result }\end{array}$ \\
\hline Hamari, 2019 & Low & High & High & Low & Low \\
Sabel, 2016 & Low & Unclear & Low & Low & High \\
Sabel, 2017 & Low & Unclear & Low & Low & Some concerns \\
Schumacher, 2018 & Unclear & Unclear & Low & Unclear & High concerns \\
\hline
\end{tabular}

Note: ${ }^{a}=$ Based on assessment using the RoB 2 tool by Sterne JAC, Savović J, Page MJ, Elbers RG, Blencowe NS, Boutron I, Cates CJ, Cheng H-Y, Corbett MS, Eldridge SM, Hernán MA, Hopewell S, Hróbjartsson A, Junqueira DR, Jüni P, Kirkham JJ, Lasserson T, Li T, McAleenan A, Reeves BC, Shepperd S, Shrier I, Stewart LA, Tilling K, White IR, Whiting PF, Higgins JPT. RoB 2: a revised tool for assessing risk of bias in randomised trials. BMJ 2019; 366: 14898

addressed the use of AVGs and/or virtual reality on physical function and cognition, but not in cancer patients [47, 48]. Staiano et al. reviewed therapeutic uses of AVGs in a variety of health conditions and ages, but only included one study with adult cancer patients and no studies with AYA cancer patients and survivors [49]. Devine et al. examined the use of digital health interventions in AYA cancer survivors but only included one study that used AVGs and videoconferencing that aimed to improve PA [50].

Interventions selected in the current review included a range of cancer diagnoses and varied considerably in the selection of outcome measures between studies. We found conflicting results for outcome measures between studies, possibly due to studies being underpowered with small sample size to detect statistically significant differences and leading to type II errors. Additionally, the majority of the studies were of low to medium quality. Another reason for the conflicting results may be due to poor adherence. Hamari et al. reported especially poor adherence and that the hospital- and homebased intervention was not followed as directed, despite having good acceptance, retention, and reported enjoyment of the intervention. As suggested by the authors, poor adherence may have resulted from the intervention being implemented too early during cancer treatment without supervision, personalized guidance, or psychosocial support. Some guardians felt the AVGs were too difficult for their children, there was too much going on for them to install the games at home during treatment, and that it was difficult to find space to exercise during hospital admissions [41]. In contrast, Rosipal et al. provided space and equipment for HSCT patients to exercise during hospitalization and reported good adherence with an average of $36.5 \mathrm{~min}$ of PA per day, although the exercises performed were not limited to AVGs [42]. Schumacher et al. also assessed HSCT patients during hospitalization, with reasons for non-compliance due to exacerbation of medical conditions and early discharge [44]. Both of the home-based interventions conducted by Wang et al. and Sabel et al. reported good adherence to the intervention, with Sabel et al. reporting illness and/or being away from home due to illness as reasons for non-compliance [43, 46].

AYAs have specific needs and preferences, including competing work and family demands, and the desire for remote participation in interventions [24]. It is crucial to identify and address these preferences to optimize participant adherence when designing interventions for this hard-to-reach population. Our review found that most interventions combined adolescent cancer survivors with younger children [41, 45, 46] or combined young adults with older adults [35, 40, 43, 44]. Although one study assessed type of AVG preference of AYA cancer survivors, the intervention served only as a recommendation in conjunction with other therapies received during the hospital visit, and there was no uniformity of AVGs utilized [42]. Only three studies delivered the intervention remotely for participants to use the AVGs at home [41, 43, 45, 46], despite this being a preference of AYAs [24]. Most AVG sessions took place in a university lab $[35,40]$ or during a hospital admission [42, 44].

All studies delivered the AVG sessions individually, and none formed groups to foster participant engagement. A group dynamic is essential because AYAs have expressed the desire for face-to-face peer support during interventions [24] over support from family and friends [51]. Additionally, groupbased PA interventions have been shown to help cancer patients improve PA levels, long-term PA adherence, and physical function [52-54] in addition to improved QOL and social support [55].

While all studies included AVGs as part of their interventions, there was minimal use of videoconferencing. Only one study utilized videoconferencing, which was used for participant follow-up and to encourage AVG engagement [45, 46]. 
No studies used videoconferencing to deliver the AVG interventions remotely, despite this method being used in other populations. For example, Google Hangout (Google LLC, Mountain View, CA) has been used to connect mothers in a group PA intervention using exercises from mobile apps [56]. Additionally, videoconferencing (Zoom Inc., San Jose, CA) was used by a health educator to lead adolescents with intellectual and developmental disabilities in conventional aerobic exercises [57]. Videoconferencing has also been used to deliver PA interventions for pediatric heart transplant patients [58], older breast and prostate cancer survivor couple dyads [59], and middle-aged adults with obesity [60]. This gap points to the need to explore the use of videoconferencing to deliver PA interventions remotely to address access barriers and maximize intervention participation by AYA cancer survivors. Furthermore, given that AYA survivors highly endorse peer support as they navigate transition challenges [28-32], combining AVG and group videoconferencing can capitalize on the "fun" factor and social connections needed to enhance motivation for PA. The integration of video game play and videoconferencing has been implemented under the Twitch platform since $2017[25,26]$. Therefore, the combination of AVG and group videoconferencing to deliver PA intervention may enhance participants' experience and engagement. Lastly, this type of intervention is even more relevant under a pandemic context to ensure ongoing programming to promote $\mathrm{PA}$ adoption among AYA cancer survivors.

Behavior change techniques have also been used to produce positive effects on PA levels, long-term maintenance of PA in cancer survivors [61, 62], and motivation to engage in PA. Self-determination theory (SDT), a theoretical framework, posits that fulfillment of basic psychological needs for autonomy, competence, and relatedness will help promote autonomous motivation and thus lead to behavior change [63]. For example, increasing autonomous motivation (defined as motivation that is relatively internal, such as motivation related to enjoyment, values, or identity) is critical for initiating and maintaining PA behavior [64, 65]. Studies that used autonomous motivation to promote PA in adolescents found an increase in PA behavior with an increase in psychological well-being [66, 67]. Additionally, many AVGs include evidence-based behavior change techniques [68] that are similar to those used in behavior interventions to promote PA [69]. Behavior change techniques within AVGs can include goal setting, feedback on PA progress, encouraging social comparison and interaction, and providing rewards [68]. AVG-based PA interventions with the addition of behavior change theory, such as SDT, resulted in a significant increase in PA and adherence to the intervention [70]. However, only one study outlined a behavior change method (task self-efficacy and physical activity enjoyment) incorporated into their intervention [43]. 


\section{Study strengths}

Our review had a number of strengths. To our knowledge, this is the first systematic review on the use of AVGs and videoconferencing in PA interventions aimed at improving physical function, PA levels, QOL, and fatigue with a focus on AYA cancer survivors. We included both experimental and observational studies to provide a diverse perspective on the current use of AVGs within the AYA cancer population. Although we were not able to specifically focus our findings among AYA cancer survivors, our review serves to highlight the limited homogeneity of physical function outcome measures, AVG prescription, and utilization in various cancer populations and settings.

\section{Study limitations}

Limitations of our systematic review include the possible exclusion of relevant studies due to removing non-English language articles and articles not available as full-text. Also, we limited interventions to those focused on PA, physical function outcomes, and quality of life. Other reviews included AVGs as a pain distraction during uncomfortable procedures [71-73] or management of pain symptoms due to disease progression $[74,75]$ for overall health, wellness of mind and body [76], and as a means to improve disease selfmanagement [47, 77]. Pain control and disease management are major factors that contribute to cancer survivors' QOL.

Some AVG studies may not have been captured, especially since new publications are produced at a high rate, despite performing a rigorous search. Due to the heterogeneity of outcome measurements, we were unable to conduct a metaanalysis. Additionally, there are limitations to the generalizability of our findings to both male and female AYA cancer survivors as there was a disproportionately high number of male participants in four out of six studies, and most studies did not focus exclusively on the AYA age range of 15-39 years. Since AYA cancer survivors have unique needs and preferences, it is possible that the results of studies that mostly included older adults were less applicable to the AYA-aged participants in those studies [35, 40, 43, 44]. Likewise, results from studies that included mostly young patients under 15 years old may be less applicable to the few AYA-aged participants $[41,45,46]$. For these reasons, we were limited to performing a qualitative analysis in this review.

\section{Conclusions}

Some studies in our review showed that AVGs hold promise for improving physical function, physical activity, QOL, and cancer-related fatigue in cancer survivors. Unfortunately, these findings' generalizability to AYA cancer survivors is limited as only one study specifically targeted cancer survivors in the AYA age range of 15-39 years. Additionally, there remains a significant dearth of high-quality published interventions. Further data analysis is limited due in part to the heterogeneity of outcome measures used between studies, small sample sizes, minimal use of randomized controlled trial study designs, and a lack of studies conducted with individuals in the AYA specific age range. Future research is needed to determine the feasibility, acceptability, and effectiveness of using AVGs to improve physical function and health outcomes in the AYA cancer population. Furthermore, there is a need to evaluate the use of videoconferencing as a means of engaging AYA cancer survivors, which can potentially optimize PA participation among this hard-to-reach population. Under the current pandemic context, this is even more relevant to ensure ongoing PA support to optimize physical function and QOL for AYA survivors.

Acknowledgements The authors would like to acknowledge medical research librarian David Farris MSIS at the University of Texas MD Anderson Cancer Center for his contribution towards the literature search he conducted and verified in preparation for this systematic review.

Code availability Not applicable.

Author contribution All authors have read and agreed to the published version of the manuscript. All authors contributed substantially to this review. The following are the specific contributions for each author. Conceptualization, U.C., S.J.W., and M.C.S.; methodology, U.C., M.C.S., and E.J.L.; validation, N.P., M.D.S., A.B., K.B.E., and S.P.; formal analysis, U.C., S.J.W., M.C.S., and N.P.; data curation, U.C. and S.J.W.; writing - original draft preparation, U.C., S.J.W., N.P., and M.C.S.; writing - review and editing, E.J.L., M.D.S., A.B., K.B.E., and S.P.; supervision, M.C.S.; project administration, S.J.W. and M.C.S.

Funding This research did not receive any specific grant from funding agencies in the public, commercial, or not-for-profit sectors. Salary support was provided in part by a Mentored Research Scholar Grant in Applied and Clinical Research (MRSG-14-165-01-CPPB) from the American Cancer Society; the Claude D. Pepper Older Americans Independence Center (OAIC) and Sealy Center on Aging (P30AG024832); the National Cancer Institute (R21CA218543); the National Institute on Aging (R01AG064092); the Center for Energy Balance in Cancer Prevention and Survivorship, Duncan Family Institute for Cancer Prevention and Risk Assessment; MD Anderson's Cancer Center Support Grant (CA016672).

Data availability Data were abstracted from published articles. An example of a search strategy is available under PROSPERO: CRD42020163491.

\section{Declarations}

Ethics approval Not applicable; this is a systematic review. Data were abstracted from published articles.

Consent to participate Not applicable; this is a systematic review. Data were abstracted from published articles. 
Consent for publication Not applicable; this is a systematic review. Data were abstracted from published articles. We did not use any individual study's published images.

Conflict of interest The authors declare no competing interests.

\section{References}

1. Isenalumhe LL, Fridgen O, Beaupin LK, Quinn GP, Reed DR. Disparities in adolescents and young adults with cancer. Cancer Control. 2016;23(4):424-33. https://doi.org/10.1177/ 107327481602300414.

2. Adolescent and Young Adult Oncology Progress Review Group. Closing the gap: research and care imperatives for adolescents and young adults with cancer. Bethesda: National Cancer Institute, National Institutes of Health, and the LIVESTRONG Young Adult Alliance; 2006.

3. American Cancer Society. Cancer facts \& figures, vol. 2020. Atlanta: American Cancer Society; 2020. p. 29-43.

4. Aubin S, Barr RD, Rogers P, Schacter B, Bielack SS, Manchester RA. What should the age range be for AYA oncology? J Adolesc Young Adult Oncol. 2011;1(1):3-10. https://doi.org/10.1089/ jayao.2011.1505.

5. Keegan TH, Ries LA, Barr RD, Geiger AM, Dahlke DV, Pollock $\mathrm{BH}$, et al. Comparison of cancer survival trends in the United States of adolescents and young adults with those in children and older adults. Cancer. 2016;122(7):1009-16. https://doi.org/10.1002/cncr. 29869.

6. Liu L, Moke DJ, Tsai K-Y, Hwang A, Freyer DR, Hamilton AS, et al. A reappraisal of sex-specific cancer survival trends among adolescents and young adults in the United States. JNCI: J Natl Cancer Instit. 2018;111(5):509-18. https://doi.org/10.1093/jnci/ djy 140 .

7. Miller KD, Nogueira L, Mariotto AB, Rowland JH, Yabroff KR, Alfano CM, et al. Cancer treatment and survivorship statistics, 2019. CA Cancer J Clin. 2019;69(5):363-85. https://doi.org/10. 3322/caac. 21565.

8. Jones JM, Fitch M, Bongard J, Maganti M, Gupta A, D'Agostino $\mathrm{N}$, et al. The needs and experiences of post-treatment adolescent and young adult cancer survivors. J Clin Med. 2020;9(5). https:// doi.org/10.3390/jcm9051444.

9. Ustün B, Kennedy C. What is "functional impairment"? Disentangling disability from clinical significance. World Psych. 2009;8(2):82-5. https://doi.org/10.1002/j.2051-5545.2009. tb00219.x.

10. Dent E, Morley JE, Cruz-Jentoft AJ, Woodhouse L, RodríguezMañas L, Fried LP, et al. Physical frailty: ICFSR International Clinical Practice Guidelines for Identification and Management. J Nutr Health Aging. 2019;23(9):771-87. https://doi.org/10.1007/ s12603-019-1273-Z.

11. Ness KK, Howell CR, Bjornard KL. Frailty and quality of life in adult survivors of childhood cancer. Expert Rev Qual Life Cancer Care. 2017;2(2):79-85. https://doi.org/10.1080/23809000.2017. 1300507

12. Ness KK, Krull KR, Jones KE, Mulrooney DA, Armstrong GT, Green DM, et al. Physiologic frailty as a sign of accelerated aging among adult survivors of childhood cancer: a report from the St Jude Lifetime cohort study. J Clin Oncol. 2013;31(36):4496-503. https://doi.org/10.1200/jco.2013.52.2268.

13. Smitherman AB, Anderson C, Lund JL, Bensen JT, Rosenstein DL, Nichols HB. Frailty and comorbidities among survivors of adolescent and young adult cancer: a cross-sectional examination of a hospital-based survivorship cohort. J Adolesc Young Adult
Oncol. 2018;7(3):374-83. https://doi.org/10.1089/jayao.2017. 0103.

14. Hayek S, Gibson TM, Leisenring WM, Guida JL, Gramatges MM, Lupo PJ, et al. Prevalence and predictors of frailty in childhood cancer survivors and siblings: a report from the Childhood Cancer Survivor Study. J Clin Oncol. 2019:Jco1901226. https://doi.org/10. 1200/jco.19.01226.

15. Armenian SH, Xu L, Cannavale KL, Wong FL, Bhatia S, Chao C. Cause-specific mortality in survivors of adolescent and young adult cancer. Cancer. 2020;126(10):2305-16. https://doi.org/10.1002/ cncr.32775.

16. Wurz A, Brunet J. The effects of physical activity on health and quality of life in adolescent cancer survivors: a systematic review. JMIR Cancer. 2016;2(1):e6. https://doi.org/10.2196/cancer.5431.

17. Carretier J, Boyle H, Duval S, Philip T, Laurence V, Stark DP, et al. A review of health behaviors in childhood and adolescent cancer survivors: toward prevention of second primary cancer. J Adolesc Young Adult Oncol. 2016;5(2):78-90. https://doi.org/10.1089/ jayao.2015.0035.

18. Rabin C. Barriers to increasing physical activity among young adult cancer survivors. J Adolesc Young Adult Oncol. 2017;6(2):372-6. https://doi.org/10.1089/jayao.2016.0056.

19. Barr RD, Ferrari A, Ries L, Whelan J, Bleyer WA. Cancer in adolescents and young adults: a narrative review of the current status and a view of the future. JAMA Pediatr. 2016;170(5):495-501. https://doi.org/10.1001/jamapediatrics.2015.4689.

20. Wurz A, Brunet J. Describing and exploring self-esteem, physical self-perceptions, physical activity and self-efficacy in adolescent and young adult cancer survivors. Euro J Cancer Care. 2019: e13179. https://doi.org/10.1111/ecc.13179.

21. Lieberman Debra A, Chamberlin B, Medina E, Franklin Barry A, Sanner Brigid M, Vafiadis DK. The Power of Play: Innovations in Getting Active Summit 2011. Circulation. 2011;123(21):2507-16. https://doi.org/10.1161/CIR.0b013e318219661d.

22. Glen K, Eston R, Loetscher T, Parfitt G. Exergaming: feels good despite working harder. PLoS One. 2017;12(10):e0186526. https:// doi.org/10.1371/journal.pone.0186526.

23. Love B, Moskowitz MC, Crook B, Thompson CM, DonovanKicken E, Stegenga K, et al. Defining adolescent and young adult (AYA) exercise and nutrition needs: concerns communicated in an online cancer support community. Patient Educ Couns. 2013;92(1): 130-3. https://doi.org/10.1016/j.pec.2013.02.011.

24. Rabin C, Simpson N, Morrow K, Pinto B. Intervention format and delivery preferences among young adult cancer survivors. Int $\mathrm{J}$ Behav Med. 2013;20(2):304-10. https://doi.org/10.1007/s12529012-9227-4.

25. Bindelglass A: Twitch adds videoconferencing to platform. http:// conferencing.tmcnet.com/topics/conferencing/articles/427926twitch-adds-videoconferencing-platform.htm (2016). Accessed December 12020.

26. Petrocelli B: The new Twitch Desktop App is here $\mid$ Twitch Blog. https://blog.twitch.tv/en/2017/08/10/the-new-twitch-desktop-appis-here-6d6a71c6ec83/ (2017). Accessed December 12020.

27. Kvedar J, Coye MJ, Everett W. Connected health: a review of technologies and strategies to improve patient care with telemedicine and telehealth. Health Affair. 2014;33(2):194-9. https://doi. org/10.1377/hlthaff.2013.0992.

28. Hydeman JA, Uwazurike OC, Adeyemi EI, Beaupin LK. Survivorship needs of adolescent and young adult cancer survivors: a concept mapping analysis. J Cancer Surviv. 2019;13(1):34-42. https://doi.org/10.1007/s11764-018-0725-5.

29. Bélanger LJ, Plotnikoff RC, Clark AM, Courneya KS. Determinants of physical activity in young adult cancer survivors. Am J Health Behav. 2012;36(4):483-94. https://doi.org/10.5993/ ajhb.36.4.5. 
30. Rabin C, Dunsiger S, Ness KK, Marcus BH. Internet-based physical activity intervention targeting young adult cancer survivors. J Adolesc Young Adult Oncol. 2011;1(4):188-94. https://doi.org/10. 1089/jayao.2011.0040.

31. Rabin C, Pinto B, Fava J. Randomized trial of a physical activity and meditation intervention for young adult cancer survivors. J Adolesc Young Adult Oncol. 2016;5(1):41-7. https://doi.org/10. 1089/jayao.2015.0033.

32. Valle CG, Tate DF, Mayer DK, Allicock M, Cai J. Exploring mediators of physical activity in young adult cancer survivors: evidence from a randomized trial of a Facebook-based physical activity intervention. J Adolesc Young Adult Oncol. 2015;4(1):26-33. https://doi.org/10.1089/jayao.2014.0034.

33. Kopp LM, Gastelum Z, Guerrero CH, Howe CL, Hingorani P, Hingle M. Lifestyle behavior interventions delivered using technology in childhood, adolescent, and young adult cancer survivors: a systematic review. Pediatr Blood Cancer. 2017;64(1):13-7. https:// doi.org/10.1002/pbc.26166.

34. Moher D, Liberati A, Tetzlaff J, Altman DG. Preferred reporting items for systematic reviews and meta-analyses: the PRISMA statement. BMJ (Clin $\backslash$ Res ed). 2009;339:b2535. https://doi.org/10. 1136/bmj.b2535.

35. Alves RD, Iunes DH, Pereira IC, Borges JBC, Nogueira DA, Silva $\mathrm{AM}$, et al. Influence of exergaming on the perception of cancerrelated fatigue. Games Health J. 2017;6(2):119-26. https://doi.org/ 10.1089/g4h.2016.0051.

36. de Oliveira PF, Iunes DH, Alves RS, de Carvalho JM, Menezes FS, Carvalho LC. Effects of exergaming in cancer related fatigue in the quality of life and electromyography of the middle deltoid of people with cancer in treatment: a controlled trial. Asian Pac J Cancer Prev. 2018;19(9):2591-7. https://doi.org/10.22034/APJCP.2018.19.9. 2591.

37. Ouzzani M, Hammady H, Fedorowicz Z, Elmagarmid A. Rayyan-a web and mobile app for systematic reviews. Syst Rev. 2016;5(1): 210. https://doi.org/10.1186/s13643-016-0384-4.

38. Sterne JAC, Savović J, Page MJ, Elbers RG, Blencowe NS, Boutron I, et al. RoB 2: a revised tool for assessing risk of bias in randomised trials. BMJ (Clin $\backslash$ Res ed). 2019;366:14898. https://doi. org/10.1136/bmj.14898.

39. Sterne JA, Hernán MA, Reeves BC, Savović J, Berkman ND, Viswanathan M, et al. ROBINS-I: a tool for assessing risk of bias in non-randomised studies of interventions. BMJ (Clin $\backslash$ Res ed). 2016;355:i4919. https://doi.org/10.1136/bmj.i4919.

40. Alves RD, Iunes DH, de Carvalho JM, Menezes FD, Silva AM, Borges JBC, et al. Effects of exergaming on quality of life in cancer patients. Games Health J. 2018;7(6):385-92. https://doi.org/10. 1089/g4h.2017.0174.

41. Hamari L, Jarvela LS, Lahteenmaki PM, Arola M, Axelin A, Vahlberg T, et al. The effect of an active video game intervention on physical activity, motor performance, and fatigue in children with cancer: a randomized controlled trial. BMC Res Notes. 2019;12(1):784. https://doi.org/10.1186/s13104-019-4821-z.

42. Rosipal NC, Mingle L, Smith J, Morris GS. Assessment of voluntary exercise behavior and active video gaming among adolescent and young adult patients during hematopoietic stem cell transplantation. J Pediatr Oncol Nurs. 2013;30(1):24-33. https://doi.org/10. $1177 / 1043454212461071$

43. Wang HL, McMillan SC, Vijayakumar N, McDonald S, Huang LT, Gwede C, et al. A behavioral physical activity intervention to manage moderate and severe fatigue among head and neck cancer patients-pre-efficacy study in the National Institutes of Health ORBIT model. Cancer Nurs. 2019;42(1):E1-E14. https://doi.org/ $10.1097 /$ ncc. 0000000000000568 .

44. Schumacher H, Stüwe S, Kropp P, Diedrich D, Freitag S, Greger N, et al. A prospective, randomized evaluation of the feasibility of exergaming on patients undergoing hematopoietic stem cell transplantation. Bone Marrow Transplant. 2018;53(5):584-90. https://doi.org/10.1038/s41409-017-0070-8.

45. Sabel M, Sjolund A, Broeren J, Arvidsson D, Saury JM, Blomgren $\mathrm{K}$, et al. Active video gaming improves body coordination in survivors of childhood brain tumours. Disabil Rehabil. 2016;38(21): 2073-84. https://doi.org/10.3109/09638288.2015.1116619.

46. Sabel M, Sjolund A, Broeren J, Arvidsson D, Saury JM, Gillenstrand J, et al. Effects of physically active video gaming on cognition and activities of daily living in childhood brain tumor survivors: a randomized pilot study. Neurooncol Pract. 2017;4(2): 98-110. https://doi.org/10.1093/nop/npw020.

47. Costa MTS, Vieira LP, Barbosa EO, Mendes Oliveira L, Maillot P, Ottero Vaghetti CA, et al. Virtual reality-based exercise with exergames as medicine in different contexts: a short review. Clin Pract Epidemiol Mental Health. 2019;15:15-20. https://oi.org/10. 2174/1745017901915010015.

48. Stanmore E, Stubbs B, Vancampfort D, de Bruin ED, Firth J. The effect of active video games on cognitive functioning in clinical and non-clinical populations: a meta-analysis of randomized controlled trials. Neurosci Biobehav Rev. 2017;78:34-43. https://doi.org/10. 1016/j.neubiorev.2017.04.011.

49. Staiano AE, Flynn R. Therapeutic uses of active videogames: a systematic review. Games Health J. 2014;3(6):351-65. https://doi. org $/ 10.1089 / \mathrm{g} 4 \mathrm{~h} .2013 .0100$.

50. Devine KA, Viola AS, Coups EJ, Wu YP. Digital health interventions for adolescent and young adult cancer survivors. JCO Clin Cancer Info. 2018;2:15-5. https://doi.org/10.1200/cci.17.00138.

51. Zebrack B, Bleyer A, Albritton K, Medearis S, Tang J. Assessing the health care needs of adolescent and young adult cancer patients and survivors. Cancer. 2006;107(12):2915-23. https://doi.org/10. $1002 /$ cncr. 22338

52. Mina DS, Sabiston CM, Au D, Fong AJ, Capozzi LC, Langelier D, et al. Connecting people with cancer to physical activity and exercise programs: a pathway to create accessibility and engagement. Curr Oncol. 2018;25(2):149-62. https://doi.org/10.3747/co.25. 3977.

53. Swartz MC, Lewis ZH, Lyons EJ, Jennings K, Middleton A, Deer RR, et al. Effect of home- and community-based physical activity interventions on physical function among cancer survivors: a systematic review and meta-analysis. Arch Phys Med Rehabil. 2017;98(8):1652-65. https://doi.org/10.1016/j.apmr.2017.03.017.

54. Leach HJ, Mama SK, Harden SM. Group-based exercise interventions for increasing physical activity in cancer survivors: a systematic review of face-to-face randomized and non-randomized trials. Support Care Cancer. 2019;27(5):1601-12. https://doi.org/10. 1007/s00520-019-04670-y.

55. Mutrie N, Campbell AM, Whyte F, McConnachie A, Emslie C, Lee $\mathrm{L}$, et al. Benefits of supervised group exercise programme for women being treated for early stage breast cancer: pragmatic randomised controlled trial. BMJ (Clin $\backslash$ Res ed). 2007;334(7592):517. https:// doi.org/10.1136/bmj.39094.648553.AE.

56. Mascarenhas MN, Chan JM, Vittinghoff E, Van Blarigan EL, Hecht $F$. Increasing physical activity in mothers using video exercise groups and exercise mobile apps: randomized controlled trial. J Med Internet Res. 2018;20(5):e179. https://doi.org/10.2196/jmir. 9310.

57. Ptomey LT, Willis EA, Greene JL, Danon JC, Chumley TK, Washburn RA, et al. The feasibility of group video conferencing for promotion of physical activity in adolescents with intellectual and developmental disabilities. Am J Intellect Develop Disabilit. 2017;122(6):525-38. https://doi.org/10.1352/1944-7558-122.6. 525.

58. Chen AC, Ramirez FD, Rosenthal DN, Couch SC, Berry S, Stauffer $\mathrm{KJ}$, et al. Healthy hearts via live videoconferencing: an exercise and diet intervention in pediatric heart transplant recipients. J Am Heart 
Assoc. 2020;9(3):e013816. https://doi.org/10.1161/JAHA.119. 013816.

59. Porter LS, Gao X, Lyna P, Kraus W, Olsen M, Patterson E, et al. Pilot randomized trial of a couple-based physical activity videoconference intervention for sedentary cancer survivors. Health Psychol. 2018;37(9):861-5. https://doi.org/10.1037/hea0000608.

60. Clark DO, Keith N, Weiner M, Xu H. Outcomes of an RCT of videoconference vs. in-person or in-clinic nutrition and exercise in midlife adults with obesity. Obes Sci Pract. 2019;5(2):111-9. https://doi.org/10.1002/osp4.318.

61. Finne E, Glausch M, Exner A-K, Sauzet O, Stölzel F, Seidel N. Behavior change techniques for increasing physical activity in cancer survivors: a systematic review and meta-analysis of randomized controlled trials. Cancer Manag Res. 2018;10:5125-43. https://doi. org/10.2147/CMAR.S170064.

62. Grimmett C, Corbett T, Brunet J, Shepherd J, Pinto BM, May CR, et al. Systematic review and meta-analysis of maintenance of physical activity behaviour change in cancer survivors. Int J Behav Nutr Phys Act. 2019;16(1):37. https://doi.org/10.1186/s12966-0190787-4.

63. Ryan RM, Deci EL. Self-determination theory and the facilitation of intrinsic motivation, social development, and well-being. Am Psychol. 2000;55(1):68-78. https://doi.org/10.1037/0003-066X. 55.1.68.

64. Ingledew DK, Markland D, Ferguson E. Three levels of exercise motivation. Appl Psychol Health Well-Being. 2009;1(3):336-55. https://doi.org/10.1111/j.1758-0854.2009.01015.x.

65. Teixeira PJ, Carraça EV, Markland D, Silva MN, Ryan RM. Exercise, physical activity, and self-determination theory: a systematic review. Int J Behav Nutr Phys Act. 2012;9(1):78. https://doi. org/10.1186/1479-5868-9-78.

66. Vaquero Solís M, Sánchez-Miguel PA, Tapia Serrano M, Pulido JJ, Iglesias GD. Physical activity as a regulatory variable between adolescents' motivational processes and satisfaction with life. Int $\mathrm{J}$ Environ Res Public Health. 2019;16(15). https://doi.org/10.3390/ ijerph16152765.

67. Lubans DR, Smith JJ, Morgan PJ, Beauchamp MR, Miller A, Lonsdale C, et al. Mediators of psychological well-being in adolescent boys. J Adolesc Health. 2016;58(2):230-6. https://doi.org/10. 1016/j.jadohealth.2015.10.010.
68. Lyons EJ, Hatkevich C. Prevalence of behavior changing strategies in fitness video games: theory-based content analysis. J Med Internet Res. 2013;15(5):e81. https://doi.org/10.2196/jmir.2403.

69. Michie S, Abraham C, Whittington C, McAteer J, Gupta S. Effective techniques in healthy eating and physical activity interventions: a meta-regression. Health Psychol. 2009;28(6):690-701. https://doi.org/10.1037/a0016136.

70. Peng W, Pfeiffer KA, Winn B, Lin J-H, Suton D. A pilot randomized, controlled trial of an active video game physical activity intervention. Health Psychol. 2015;34S:1229-39. https://doi.org/10. 1037/hea0000302.

71. Sander Wint S, Eshelman D, Steele J, Guzzetta CE. Effects of distraction using virtual reality glasses during lumbar punctures in adolescents with cancer. Oncol Nurs Forum. 2002;29(1):E8-E15.

72. Indovina P, Barone D, Gallo L, Chirico A, De Pietro G, Giordano A. Virtual reality as a distraction intervention to relieve pain and distress during medical procedures. Clin J Pain. 2018;34(9):85877. https://doi.org/10.1097/AJP.0000000000000599.

73. Hoffman HG, Patterson DR, Seibel E, Soltani M, Jewett-Leahy L, Sharar SR. Virtual reality pain control during burn wound debridement in the hydrotank. Clin J Pain. 2008;24(4):299-304. https:// doi.org/10.1097/AJP.0b013e318164d2cc.

74. Chi B, Chau B, Yeo E, Ta P. Virtual reality for spinal cord injuryassociated neuropathic pain: systematic review. Ann Phys Rehabil Med. 2019;62(1):49-57. https://doi.org/10.1016/j.rehab.2018.09. 006.

75. Jibb LA, Nathan PC, Stevens BJ, Seto E, Cafazzo JA, Stephens N, et al. Psychological and physical interventions for the management of cancer-related pain in pediatric and young adult patients: an integrative review. Oncol Nurs Forum. 2015;42(6):E339-E57. https://doi.org/10.1188/15.Onf.E339-e357.

76. Horowitz S. Exercise to promote mind-body health in patients with cancer. Alter Complement Ther. 2012;18(4):186-91. https://doi. org/10.1089/act.2012.18402.

77. Fernandes CS, Magalhaes B, Santos C, Martines-Galiano J. The use of games in the self-management of oncological disease: an integrative literature review. Online J Nurs Informat. 2019.

Publisher's note Springer Nature remains neutral with regard to jurisdictional claims in published maps and institutional affiliations. 